\title{
A Sustainable Model for OpenCourseWare Development
}

Justin Johansen

David Wiley

david.wiley@gmail.com

Follow this and additional works at: https://scholarsarchive.byu.edu/facpub

Part of the Educational Psychology Commons

\section{Original Publication Citation}

J. Johansen and D. Wiley, "A Sustainable Model for OpenCourseWare Development", Educational Technology Research and Development, May 21.

\section{BYU ScholarsArchive Citation}

Johansen, Justin and Wiley, David, "A Sustainable Model for OpenCourseWare Development" (2010). Faculty Publications. 103.

https://scholarsarchive.byu.edu/facpub/103 


\title{
A Sustainable Model for OpenCourseWare Development
}

Justin Johansen \& David Wiley

\begin{abstract}
The purposes of this study were to (a) determine the cost of converting BYU Independent Study's elearning courses into OpenCourseWare, (b) assess the impact of opening those courses on paid enrollment in the credit-bearing versions of the courses, and (c) use these data to judge whether or not an OpenCourseWare program could be financially self-sustaining over the long-term without grant monies or other subsidies. The findings strongly suggest that the BYU Independent Study model of publishing OpenCourseWare is financially selfsustaining, allowing the institution to provide a significant public good while generating new revenue and meeting its ongoing financial obligations.
\end{abstract}

Keywords: OpenCourseWare, sustainability, open educational resources, development, cost

\section{Introduction}

For centuries, universities have been repositories of human knowledge and the primary laboratories for intellectual advancement. At the same time, access to universities has been reserved for the privileged few who could afford to attend. While higher education has become more accessible in recent decades, the opportunity to attend a university is still beyond the reach of many people in the developed world and most people in the developing world.

In October 2002, the Massachusetts Institute of Technology (MIT), one of the most prestigious universities in the world, launched the MIT OpenCourseWare Initiative, effectively tearing down the walls that kept the masses from enjoying the knowledge and instruction available to its students. OpenCourseWare (OCW) is founded on the idea that human knowledge is the shared property of all members of society. Institutions that contribute to OpenCourseWare projects grant anyone free access to their course materials. Since the materials are published under an open license, others do not need to request permission to reuse them. Since MIT launched its OCW project in 2002, it has made materials from over 1,900 of its undergraduate and graduate-level courses freely available (http://ocw.mit.edu/). MIT’s OCW Evaluation Report 
states that users include Self Learners (46.5\%), Students (32.0\%), Educators (16.4\%), and Others (5.2\%) (MIT OpenCourseWare, 2006).

Since 2002, the OCW movement has reached far beyond MIT. Over 200 institutions around the world have joined to form the OCW Consortium, openly publishing over 8,000 courses in a variety of languages. These institutions share a common commitment to increasing access to education, improving the quality of education, and empowering both well-served and underserved populations through the power of open learning (OpenCourseWare Consortium, n.d.).

\section{Distance Learning at BYU}

Brigham Young University (BYU) offers distance learning courses through its Independent Study program. Part of BYU Independent Study’s (BYU IS) mission is to create access to educational opportunities by offering courses to “anyone, anytime, anywhere.” BYU IS currently offers 591 online courses (218 university, 213 high school, and 80 personal enrichment) and 503 paper-based correspondence courses (251 university, 211 high school, and 41 personal enrichment courses). BYU IS had 165,026 total course enrollments in 2008 (22,762 university; 118,859 high school; 1,599 personal enrichment; and 21,806 free personal enrichment).

BYU IS operates on an open admission and open enrollment model: anyone may take a course through BYU IS without being formally admitted to the university. Participants may enroll in any course at any time and have up to one year to complete each course. Students work independently and at their own pace. All students are required to take final exams, under the supervision of a proctor, and they must pass the exams to pass the course. The BYU IS model focuses on minimizing costs for students by controlling content development costs, using technology to manage support expenses, building courses that minimize the use of costly textbooks (where possible), and avoiding the use of copyrighted materials. 


\section{OpenCourseWare and BYU Independent Study}

Despite its history of creating accessible and affordable distance learning courses, BYU IS has yet to engage in a program of open sharing like OpenCourseWare. Open publishing programs at other universities have been primarily grant-funded, and long-term sustainability has been a significant problem for these programs. BYU IS, on the other hand, is supported by the tuition revenue its courses generate. It does not receive financial support from the university, from the Church of Jesus Christ of Latter-day Saints, from grants, or from any other external sources.

To avoid unanticipated negative impacts to the ongoing operations of the BYU IS program, its administrators must make changes to its business model carefully, and with clearly defined strategies. Additionally, the organizational culture at BYU encourages launching programs only after clearly defining strategies and resources to ensure their long-term sustainability and success. The closing of Utah State University's OCW program due to funding issues (Parry, 2009) illustrates the fact that financial challenges surround the viability of open publishing programs. Before an OCW program within BYU IS will be possible, questions about cost, impact on paid enrollment, and financial sustainability need to be addressed.

This study empirically addresses some of the questions surrounding BYU IS’s possible participation in OCW. These questions are:

1. How much does it cost to "open” an existing BYU IS course?

Understanding the costs associated with opening BYU IS courses is essential to building a model for financial sustainability. Costs include factors such as the labor to covert courses to an OCW format, scrubbing of content to remove copyrighted material, using or buying necessary hardware and software, and providing other supplies.

2. How does opening a BYU IS course affect paid enrollments in the course? Tuition revenue from paying students supports BYU IS. If fewer people pay to enroll because they choose to use only the free content from the OCW course, then the true cost of opening a 
BYU IS course would be higher than simply the cost of converting or opening the course. Alternatively, if offering the OCW course increases the number of students who choose to pay to enroll in the regular course for credit, then OCW could generate new tuition revenue to offset the conversion cost.

3. If the impact on paid enrollments is positive, is it enough to sustain an ongoing open publishing initiative at BYU IS?

If offering OCW courses attracts new paid enrollments, the profit from those additional enrollments could offset the expense of offering OCW courses, making the program selfsustainable.

Discovering the answers to these three questions is critical for BYU to determine how and to what extent Independent Study can feasibly participate in a program of open publishing. Answers to these questions may also be useful for other institutions considering an OCW program.

\section{Literature Review}

Precious little has been published on the sustainability or costs of OCW initiatives. This section summarizes the available literature, along with data extrapolated from publically available sources and information from personal communications with representatives of OCW organizations.

\section{The Cost of Opening OpenCourseWare Courses}

It would be ideal to base cost estimates for this study on cost data from distance learning programs similar to BYU IS. However, while there are over 200 member institutions in the OCW Consortium, very few distance learning programs currently participate. Perhaps this is 
due in part to fear or uncertainty about the effect an OCW program will have on paid enrollment in distance learning courses.

Several sources in the literature provide models for identifying the costs involved in producing online courses. Bartolic-Zlomislic and Bates (1999) point out that the cost structures underlying the development of online courses are very different from those of face-to-face teaching or print-based distance education. Chapman and colleagues (2006) concur, estimating a ratio of 220 hours of production time for every hour of e-learning to be created and a ratio for classroom instruction of only 36:1. Sources that cite specific costs for development vary widely on their estimates. Boettcher (2004) estimates $\$ 25,000$ per credit hour, or $\$ 75,000$ for a threecredit online course, while Burson (2003) calculates $\$ 191,822$ for an online course. Downes (2001) actually reports a \$4,000 estimate for development of an online course on the low end of the scale.

This study does not consider the costs to produce new online courses directly. Rather, we are interested in the cost of opening access to existing courses, which should be considerably less expensive than developing new courses. While there is no published cost data from distance learning institutions, some traditional OCW projects have made their cost data available. The MIT OCW Evaluation Findings report (MIT OpenCourseWare, 2006) states MIT OCW's cost to open a course as ranging from $\$ 10,000-\$ 15,000$ per non-video-based course to $\$ 30,000$ per video-based course.

Utah State University (USU) reported that their cost to open one course was approximately \$5,000 (Wiley, 2007). USU’s expenses came primarily from the labor costs of the personnel working on USU's open publishing initiative. USU's open publishing team consisted of a full-time Director, two half-time graduate students, and three half-time undergraduate students. USU also opened some courses with no direct cost by having students and graduate students publish courses as class projects.

One challenge in discussing the costs of opening courses is the different ways that institutions define a "course.” Both MIT and USU define an OCW “course” as a publication 
of those materials used to teach the course on campus. The Open University of the Netherlands (OUNL), a distance learning institution, defines an OCW course as twenty-five study hours of content. Their open publishing initiative was funded by grants of approximately $€ 660,000$ (\$858,000), equating to an average of $\$ 34,320$ per OCW course published (R. Schuwer, personal communication, December 18, 2008).

Like OUNL, the OpenLearn Initiative of the Open University in the United Kingdom (OUUK), another distance learning institution, does not publish complete courses. Instead, they publish "samples" of courses to let OCW users see a portion of a course. One of the OUUK's goals in providing course samples is to covert OCW users into paying students. Each course sample has a button that students can click to "enroll now" to complete and earn credit for the full course. OUUK has opened course samples for approximately $40 \%$ of the course catalog, with the average sample consisting of approximately 11 hours of instruction. The OUUK's average cost for opening one study hour of legacy material is about $£ 350$ (\$535), or $\$ 5,885$ for the average 11-hour sample (A. Lane, personal communication, December 5, 2008).

For this BYU IS study, "course" is defined as "those materials, less the graded course assessments, used to teach the Independent Study version of a course.” BYU IS's approach to producing courses offers some cost advantages when converting courses to an OCW format. First, BYU IS limits the number of expensive textbooks used in its courses. In fact, many of the high school courses BYU IS offers do not require a textbook at all. Instead, BYU IS makes a significant investment during the development process to create content-complete and media-rich courses. Accordingly, while most OCW programs offer partial courses, many BYU IS courses are complete and comprehensive. The courses chosen for the pilot, fall into this category.

Second, most OCW courses are converted from traditional face-to-face courses. The process of converting those courses for OCW often involves digitizing paper-based materials (originally developed for the classroom) into a format appropriate for online delivery. In contrast, BYU IS courses are designed from the beginning for Internet delivery and do not need 
digitizing to create an OCW offering. However, the courses do require some modification (e.g., removing graded assessments, revising instructions, and adding the Creative Commons license).

Third, BYU IS benefits from its minimal use of copyrighted materials, as well as from favorable contractual terms with faculty which reserve intellectual property rights for the institution. This prevents BYU IS from incurring as many “copyright scrubbing” costs as most other OCW projects. Copyright scrubbing includes identifying copyrighted content in a course, identifying the rights holder, negotiating for rights to use the material, and paying any applicable license fees. This scrubbing cost, which is almost non-existent for BYU IS in converting its courses to OCW format, can be one of the most expensive aspects of converting courses to OCW. These unique aspects of the BYU IS courses make it possible to convert most courses to OCW at a significantly lower per-course cost.

This study used USU's course conversion costs as a baseline for estimating how much it would cost to convert BYU IS courses to OCW. USU was considered the best example for course conversion costs, because their definition of a course and the content they converted to OCW was similar to BYU IS’s. USU’s average cost to open a course was $\$ 5,000$ (Wiley, 2007). Because of the content-complete nature of the selected BYU IS courses and the program's limited use of copyrighted materials, it was estimated that courses could be converted at a savings of 20\%-40\% less than USU's per-course cost, or approximately $\$ 3,000$ to open each BYU IS course. When making these estimates, the lack of published information on course conversion costs for existing OCW programs spoke to the need for carefully and empirically collected data on the direct costs of opening courses.

\section{The Impact of Opening an OCW Course on Paid Enrollments in that Course}

The OpenLearn Initiative at Open University in the United Kingdom (OUUK) was the best comparable program to use when considering the impact opening courses could have on BYU IS. The OUUK has approximately 200,000 course enrollments and 130,000 students each

year, similar in scale to BYU IS. In two years of offering course samples, 7,800 enrollments have 
come from people who used the "enroll now" button in the OUUK's course samples to convert to a fully paid enrollment (A. Lane, personal communication, December 5, 2008). This means that approximately $1.95 \%$ of the OUUK's enrollment over the past two years has come through conversions from free OCW users into paid course enrollments. Approximately $33 \%$ of those conversions were people who were new to the OUUK system, meaning that approximately $0.64 \%$ of OUUK's entire enrollment for a given year were new users that converted to paid enrollment from a free course sample. That equates to an average of approximately 1,280 new paying students converted through course samples each year.

Similarly, the Open University of the Netherlands reported that 18\% of OCW users were "inspired to purchase an academic course" based on their interactions with OUNL OCW (Eshuis, 2009). The University of California-Irvine (UCI) also launched an OCW offering in November 2006 with a "click to enroll" feature. They report that their OCW site has consistently generated more site traffic and more sales leads than any other form of advertising (K. Tam, personal communication, June 4, 2009).

No other data on the impact of OCW on paid enrollments was available at the time of this study. This dearth of data further underscores the importance of the current study.

\section{Sustaining an Ongoing Open Publishing Initiative}

Many question whether a project whose primary goal is giving things away can be meaningfully self-sustaining. This study focuses on the issue from a purely financial standpoint. However, consideration should also be given to how OCW aligns with and supports the mission and strategy of an institution or organization. By empirically examining the impact of OCW on paid enrollment, BYU IS will be able to weigh the financial sustainability of OCW as a part of a larger strategic discussion of other factors such as organizational mission, community outreach, marketing, retention, student satisfaction, learning achievement, and so forth.

From a financial perspective, there do not appear to be any organizations currently running large scale, self-sustaining open publishing initiatives. In fact, some projects have 
already stopped active development due to lack of ongoing funding. For example, when their grants ended, the Foothill De Anza Community College District's SOFIA project (http://sofia.fhda.edu/) stopped producing new courses. Additionally, the Utah State University OCW initiative's legislative funding has ended, and there are no longer any personnel at USU working on OCW courses (http://ocw.usu.edu/).

Even MIT OCW, the leader of the OCW movement, must raise over \$3,500,000 each year to sustain operations. Outside of donations and budgetary support from the university, another external funding source for MIT is the revenue earned from Amazon.com as OCW courses refer users to Amazon to buy the textbooks they need to completely engage with their open courses. In speaking about the importance of user contributions, MIT OCW Director Cecilia d'Oliveira (2009) wrote that MIT OCW “must continue to demonstrate that our user community can be an important piece of our ongoing funding model.”

Downes (2007) and Wiley (2007) have both written on sustainability models for OCW. Downes defined eight models, including an endowment model, a membership model, a donations model, and a conversion model.

Social movements often involve passionately committed individuals who volunteer their resources to efforts with varying degrees of centralized control and coordination. Wiley (2007) discussed the different OCW funding approaches of MIT, USU, and Rice University to illustrate how institutions differ in terms of centralization, coordination, and use of volunteer support in supporting OpenCourseWare.

1. MIT - MIT's funding model for OCW is highly centralized, very coordinated, and relies on little volunteer support. MIT supports its OCW initiative as part of its institutional mission, funding 50\% of its OCW budget through the university’s annual budget and deploying institutional resources to help raise the other 50\% through donor contributions. Full-time university personnel centrally coordinate support of MIT’s OCW initiative, relying on little volunteer support for ongoing operations. 
2. USU - USU's OCW project was centrally managed but externally funded and volunteer supported. Faculty members and students volunteered to support the full and part-time USU staff assigned to support the university's OCW projects.

3. Rice University - Rice's OCW project is called Connexions. Connexions is decentralized, user coordinated, and almost entirely dependent on volunteer support. Connexions is managed by a global open-source community that contributes content and manages the Connexions software platform; its user support is similar to the open source community behind Linux and OpenOffice.

As noted, this study uses the conversion model for BYU IS's OCW courses. The study was centrally supported, coordinated by full-time BYU personnel, and did not rely on volunteer support. By “conversion model," we mean that BYU IS OCW users had the opportunity to convert from viewing the OCW version of a course to enrolling in the credit-bearing version of the course by paying the regular tuition and completing the course assessments.

\section{Licensing OpenCourseWare Content Using Creative Commons Licenses}

Practically all OCW content is published under a copyright license called Creative Commons. Creative Commons (CC) licenses designate content as freely / openly published, and make it possible for search engines, including Google and Yahoo, to discover and specifically catalog OCW content. OCW publishers can publish content under different versions of the CC license, thereby granting various permissions to OCW users.

The courses opened for this study are licensed using the Attribution Non-Commercial Share Alike (BY-NC-SA) license that indicates users should cite BYU as the original source, that they can use content only for non-commercial purposes, and that content users must openly license any derivative works. BY-NC-SA is the license assigned to most OCW content worldwide. 


\section{Method}

For this study, BYU IS converted three university courses and three high school courses to OpenCourseWare offerings. The cost of opening each course was carefully tracked. Using cost and enrollment data, an analysis of the financial self-sustainability of opening BYU IS courses was conducted. This section describes the course selection process, the data collection process, and the analysis methods the study used to address each of the three research questions:

1. How much does it cost to "open” an existing BYU IS course?

2. What is the impact of opening a BYU IS course on paid enrollments in the course?

3. If the impact on paid enrollments is positive, is it enough to sustain an ongoing open publishing initiative within BYU IS?

\section{Selecting Courses for the Study}

There are many potential risks associated with opening BYU IS courses, the most serious of which is that doing so could negatively impact paid enrollment and, therefore, the revenue that sustains the BYU IS program. Given the risks and lack of empirical data, the BYU administration expected BYU IS to proceed with caution but agreed to support this project as a limited pilot. To minimize the potentially negative financial impact on BYU IS, we restricted the scope of the pilot, as well as limiting the initial to a period of six months, at which time it was to be reevaluated. Limiting the scope of the study was essential to receiving authorization to proceed.

Courses were chosen (as much as possible) based on these criteria:

1. The courses should have at least six months of enrollment history.

2. There must have been at least one other BYU IS course with a comparable enrollment pattern, and at least six months of enrollment history, as a control.

3. Selected courses should have an adequate number of enrollments per year to provide sufficient data for the study. 
4. The courses should represent a wide range of subject areas.

5. The pilot would include only courses for which there was support from the faculty for the project.

6. The courses should represent the "norm" among BYU IS courses in terms of quality, use of media, and inclusion of copyrighted materials.

Following these criteria, the following university courses were chosen for inclusion in the study:

1. Theater Media Arts 150 (TMA 150) - Public Speaking

2. Business Management 418 (BUSM 418) - Personal Finance

3. School of Family Life 110 (SFL 110) - Cooking in the Home

The following high school courses were also selected for inclusion the study:

1. Government 45 (GOVT 45) - United States and Citizenship

2. Geography 41 (GEOG 41) - World Geography

3. Earth 41 (EARTH 41) - Earth Science, Part 1

\section{Tracking the Cost to "Open" an Existing BYU IS Course}

The BYU IS cost tracking system was used to determine how much it cost to open each course. BYU IS employees who worked on converting courses for this study billed their time using that system, and their reported hours and actual salaries were used to determine the costs of converting each course to the OCW format. Existing technical infrastructure (e.g., servers, software, and office space) was used, and the costs for additional storage and bandwidth were negligible.

\section{Measuring the Impact of Opening a BYU IS Course on Paid Enrollments in the Course}

A variety of technologies, including browser cookies and Google Analytics, were used to track the number of people who visited an OCW course but did not pay to enroll in a course, the number of people who visited an OCW course and later registered via the regular online 
registration process (instead of using the “click to register” button inside an OCW course), and the number of people who visited an OCW course and registered to earn credit in the course by using the "click to register" button inside an OCW course. From these data we were able to calculate the rate at which OCW visitors converted to paid enrollments and the number of enrollments attributable to the OCW website.

\section{Sustaining OpenCourseWare Within BYU IS}

For OpenCourseWare to be sustainable, the cost of opening courses must be less than the incremental profit per enrollment multiplied times the number of new enrollments attributable to the OCW courses, as follows:

(Cost to open) < (Profit per enrollment) x (New attributable enrollments)

Using cost and enrollment data gathered to answer the first two research questions, an

analysis was performed to make an initial estimate of the financial sustainability of a long-term open publishing initiative within BYU IS.

\section{Results}

Data was collected and analyzed as described above in order to answer the three questions of the study:

1. How much does it cost to "open” an existing BYU IS course?

2. How does opening a BYU IS course affect paid enrollments in the course?

3. If the impact on paid enrollments is positive, is it enough to sustain an ongoing open publishing initiative at BYU IS? 


\section{The Cost to Open Courses}

Converting a course to the OCW format incurred three types of expenses:

1. Infrastructure such as hardware, software, office space, and supplies.

2. Royalties and license fees for the use of copyrighted materials in the OCW course.

3. Labor costs, including converting the material to a digital format, removing graded assessments, and “copyright scrubbing” the content to remove or replace copyrighted materials.

\section{Hardware, software, materials, and supplies used to open courses}

The six courses that were converted to OCW had already been developed for tuitionpaying BYU IS students. The OCW sections reused that previously developed content and were delivered on existing hardware and software infrastructure. The conversion process did not require any purchase of special supplies or materials. The total cost of hardware, software, office space, and supplies for the study was therefore negligible because the study occurred within BYU IS’s established infrastructure.

It is important to note that while these costs were negligible in the context of this pilot study, if BYU IS converts many more of its 591 online courses, the required computer storage capacity, software, office space, and computer hardware could increase and add to the cost.

\section{Royalties and license fees to open courses}

No copyright or licensing fees were paid as part of the OCW publication process. BYU IS avoids the use of copyrighted materials whenever possible. Additionally, the BYU IS compensation model reserves intellectual property rights to the institution, meaning that no royalties were paid to content authors for use of their material in the OCW courses. In the few cases where copyrighted content was present in the selected courses, it was simply removed or 
masked during the conversion process. OCW users should be able to work through the courses even without the removed content, though ideally it would be replaced or licensed for use.

\section{Labor costs to open courses}

The primary expense of opening the six BYU IS courses was developing the software tools necessary to convert the courses from their existing format into one appropriate for OCW publication. The BYU IS courses were originally developed and stored using XML, a presentation-independent format that allows content to be automatically converted into multiple formats using software-based "transforms." The first step in converting the BYU IS courses was to develop a new XML transform that removed all graded assessments, applied the Creative Commons license to the course pages, and reformatted the content for delivery as OCW. Because BYU IS has historically used different approaches in the development of the university and high school courses, the two types of courses required two XML transforms.

The transforms had to be developed in the context of an actual course conversion. The expense of developing each transform was incurred, and therefore billed to, the first universitylevel course (TMA 150) and the first high-school course (GOVT 45) respectively. Consequently, the cost to open the first of each course type was much higher than the cost for the subsequent courses; thus, the cost to open the first of each course type is not representative of the anticipated cost of opening future courses. The first university course cost $\$ 3,485.07$ to open, while the average cost to open the second and third university courses was \$284.12. Likewise, the first high school course cost $\$ 5,204.34$ to open, and the average cost to open the second and third courses was $\$ 1,172.71$. The original development of the high school courses had taken a slightly different approach, so it was more labor intensive to convert them. The transforms were reused on the second and third university and high school courses with only minor modifications. Those transforms are now available for use with little or no additional modification should BYU IS choose to open more courses. The costs of opening the second and third courses in each category are representative of the likely cost to open additional courses should BYU choose to do so. 
As noted, the labor costs of opening the courses were tracked using BYU IS's project billing system, in which anyone who worked on the conversion projects billed their time to the courses they worked on. A project manager ensured that workers billed their time each week. The system used each person's actual wage and the number of hours they billed to calculate the labor expense of opening each course. Labor costs included (a) the development of the transforms, (b) the content conversion process, (c) course review, (d) copyright review, (e) administrative and planning, and (f) any other labor used in the conversion process.

Tables 1 and 2 summarize the total labor costs for opening each course.

Table 1

University Cost

Cost to Convert University Courses

Course Cost to Convert

TMA 150

$\$ 3,485.07$

BUS M418

$\$ 320.09$

SFL 110

$\$ 248.15$

Table 2

High School Cost

Cost to Convert High School Courses

Course Cost to Convert

GOVT 45

$\$ 5,204.34$

EARTH 41

$\$ 1,203.78$

GEOG 41

$\$ 1,141.64$ 
Based on these data points, should BYU IS choose to open additional university courses, the estimated cost would be approximately $\$ 284.00$ per course. It is unlikely that modifications to the university transform could further reduce the cost. Should BYU IS choose to open additional high school courses, the estimated cost would be approximately $\$ 1,173.00$ per course. However, modifying the high school course development and conversion processes to more closely resemble the university course processes could further reduce the cost of opening additional high school courses. Completing the OCW course conversions in the context of the regular course revision cycle, or during scheduled course updates, could realize further efficiencies (and lower costs) for both the university and high school courses.

\section{The Impact of OCW on Paid Enrollment in BYU IS Courses}

Google Analytics tools collected information about visitor traffic to the six OCW courses during the study period. A cookie was also placed in users’ browsers when they visited any OCW course in order to track OCW visitors who later registered in a regular BYU IS course. Another cookie was added to users' browsers if they used the "click to enroll” button to convert to a paid enrollment.

The OCW course sites had 20,148 visits during the six months of the study. Those 20,148 visits to OCW courses resulted in 512 paid enrollments, for a conversion rate of $2.54 \%$. The BYU IS OCW website is a very efficient marketing tool in terms of the percentage of contacts who become paying customers. This finding is similar to UC Irvine's unpublished experience described in the literature review.

The cookies that tracked enrollments following a visit to OCW functioned like the code on an advertising instrument that asks customers to enter a "promotional code" at the point of purchase. The code lets the advertiser track the number of sales that resulted from a certain form of advertising (e.g., a radio ad or billboard). The cookies used for this study tracked OCW visitors' paid enrollments in much the same way. 
Of the 512 total enrollments from OCW visitors, 464 were from people who visited on OCW course and later enrolled through BYU IS's regular Web-based registration. Of those 464 enrollments, 163 were enrollments in university courses and 301 were in high school courses. Of the 512 total enrollments, 48 came from OCW users who clicked the "enroll" button inside an OCW course. Of those, 25 were enrollments in university courses and 23 were enrollments in high school courses.

\section{Sustainability of OCW within BYU IS}

For the purposes of this study, OCW visitor enrollments were divided into two categories:

1. Weakly Attributable - a visitor enrolled in a BYU IS course at any time after viewing an OCW course (for example, if the visitor viewed an OCW course and enrolled a week later through the regular BYU IS online registration process).

2. Strongly Attributable - a visitor enrolled using the "enroll now" button inside an OCW course.

The cookies that identified enrollment from OCW visitors did not track which courses people viewed before paying to enroll in a course. Table 3 shows a summary of the number of paid enrollments attributable to each OCW course each month.

Table 3

Average Monthly Attributable Enrollments Per OCW Course

\begin{tabular}{lcc}
\hline \multicolumn{1}{c}{ Course } & Strong & Weak \\
\hline University Courses & 1.39 & 9.06 \\
High School Courses & 1.28 & 16.72
\end{tabular}

If the conversion rates for the six months of the study are typical, then an average of 108.67 new university enrollments and 200.67 new high school enrollments could be expected each year for each OCW course under the weakly attributable model. Under the strongly 
attributable model, 16.67 new university enrollments and 15.33 new high school enrollments could be expected each year from each OCW course.

While incremental improvements are constantly made to BYU IS courses, they go through a major course redesign every four years on average. Therefore, BYU IS assumes a fouryear lifecycle to estimate ROI when funding course projects. Likewise, OCW versions of BYU IS courses would need to be redeveloped every four years to keep them in alignment with the current BYU IS courses. To be sustainable over the long term, the return on investment (ROI) period for openly published courses would therefore have to average four years or less.

Tables 4 and 5 illustrate the profit margins that BYU IS would have to maintain for OCW to be a long-term, financially self-sustaining initiative (assuming a 4-year ROI period). In this context, "self-sustaining” means that the profits from new paid enrollments attributable to openly published courses over the ROI period must be equal to the cost of opening the courses. Table 4 uses figures based on strongly attributable enrollments. Table 5 uses figures based on weakly attributable enrollments.

Table 4

Sustainability - Strongly Attributable Enrollments

\begin{tabular}{ccccccc}
\hline $\begin{array}{c}\text { Course } \\
\text { Type }\end{array}$ & $\begin{array}{c}\text { Estimated } \\
\text { Conversion } \\
\text { Cost }\end{array}$ & $\begin{array}{c}\text { ROI } \\
\text { Years }\end{array}$ & $\begin{array}{c}\text { Anticipated } \\
\text { 4-Year } \\
\text { Enrollment }\end{array}$ & $\begin{array}{c}\text { Typical } \\
\text { Tuition } \\
\text { Rate }\end{array}$ & $\begin{array}{c}\text { Estimated } \\
\text { 4-Year } \\
\text { Revenue }\end{array}$ & $\begin{array}{c}\text { Margin } \\
\text { Required for } \\
\text { Sustainability }\end{array}$ \\
\hline University & $\$ 284.12$ & 4 & 66.67 & $\$ 444.00$ & $\$ 29,600.00$ & $0.96 \%$ \\
High School & $\$ 1,172.71$ & 4 & 61.33 & $\$ 124.00$ & $\$ 7,605.33$ & $15.42 \%$ \\
All Courses & $\$ 728.42$ & 4 & & & $\$ 18,602.67$ & $3.92 \%$
\end{tabular}

Table 5 
Sustainability - Weakly Attributable Enrollments

\begin{tabular}{ccccccc}
\hline $\begin{array}{c}\text { Course } \\
\text { Type }\end{array}$ & $\begin{array}{c}\text { Estimated } \\
\text { Conversion } \\
\text { Cost }\end{array}$ & $\begin{array}{c}\text { ROI } \\
\text { Years }\end{array}$ & $\begin{array}{c}\text { Anticipated } \\
\text { 4-Year } \\
\text { Enrollment }\end{array}$ & $\begin{array}{c}\text { Typical } \\
\text { Tuition } \\
\text { Rate }\end{array}$ & $\begin{array}{c}\text { Estimated } \\
\text { 4-Year } \\
\text { Revenue }\end{array}$ & $\begin{array}{c}\text { Margin } \\
\text { Required for } \\
\text { Sustainability }\end{array}$ \\
\hline University & $\$ 284.12$ & 4 & 434.67 & $\$ 444.00$ & $\$ 192,992.00$ & $0.15 \%$ \\
High School & $\$ 1,172.71$ & 4 & 802.67 & $\$ 124.00$ & $\$ 99,530.67$ & $1.18 \%$ \\
All Courses & $\$ 728.42$ & 4 & & & $\$ 146,261.33$ & $0.50 \%$
\end{tabular}

As the tables show, enrollments that can be weakly attributed to OCW generate enough additional revenue that the profit margin for university courses would need to be $0.11 \%$ of tuition to cover the cost of opening a course (this assumes that the entire margin would be dedicated to funding OCW courses). Taking a more conservative approach and only attributing to OCW those enrollments that occurred when an OCW user clicked the "enroll now" button inside a course, the required profit margin for sustainability of university OCW courses increases to $1.00 \%$. High school courses were more expensive to convert to OCW. Depending on the revenue from weakly attributable enrollments would require a marginal profit of $0.79 \%$ over four years to recover the cost of opening a course. Relying solely on the strongly attributable enrollments would require a marginal profit of $11.80 \%$ over four years to break even.

When the data for university and high school courses are combined, the overall BYU IS profit margin required for sustainability under the strongly attributable model is $3.81 \%$ and the margin required for sustainability under the weakly attributable model is $0.36 \%$. If BYU IS's profit margins are higher than those required for sustainability, then a long-term OCW initiative at BYU IS could be revenue positive. 


\section{Discussion}

\section{Contribution}

The purpose of this study was to determine the cost of opening BYU IS courses, the impact of opening those courses on paid enrollment, and whether or not a program of giving away online course materials could be financially sustained over the long-term without grant monies or other subsidies. The study strongly suggests that it is possible to create a financially self-sustaining open publishing program by which an institution simultaneously provides a significant public good and meets its ongoing financial obligations. Empirically demonstrating this possibility was critical at a time when OpenCourseWare initiatives around the globe are casting about for post-grant funding models, and some are even suspending their activities for economic reasons.

\section{Limitations and Future Directions}

While the study carefully examines the number of new enrollments that came through the OCW channel, it does not account for potential drops in enrollment attributable to the existence of the OCW courses. Informal visual inspection of enrollment data do not suggest that any such drop has occurred, but more longitudinal data must be gathered before the question of potential drops in enrollment can be answered statistically. We are currently gathering this data with the intent to report these findings in the future.

While we know the number of enrollments that came through the OCW sites, we do not know the role the OCW sites played in students' enrollment decisions. Collecting and analyzing this data will help us better determine the break-even point between the conservative strongly attributable model and more liberal weakly attributable models reported above. 
We should also explore the reasons why OCW users chose to pay to enroll in a course. Perhaps it is as simple as the need for credit, but better understanding users' motives and needs would help inform the future direction of an OpenCourseWare program within BYU IS.

Overall, the current study provides encouraging evidence that OpenCourseWare programs can be conducted in a financially self-sustaining manner. We hope these findings will encourage additional research in the developing area of open educational resources. 


\section{References}

Bartolic-Zlomislic, S. \& Bates, A. W. (1999). Investing in on-line Learning: potential benefits and limitations. Canadian Journal of Communication, 24(3). Retrieved from http://www.cjconline.ca/index.php/journal/article/viewArticle/1111/1017

Boettcher, J. V. (2004). Online course development: what does it cost? Campus Technology, July. Retrieved from http://campustechnology.com/Articles/2004/06/Online-Course-Development-What-Does-It-Cost.aspx

Burson, J. A. (2003). Cost of university-based online, distributed, and traditional learning. (Unpublished doctoral dissertation). University of Southern California, Los Angeles, CA. UMI\# AAT 3103863

Chapman, B. and the staff of Brandon Hall Research. (2006). PowerPoint to e-learning development tools: comparative analysis of 20 leading systems. Brandon Hall Research, Sunnyvale, CA.

Creative Commons. (2009). Retrieved from http://creativecommons.org/about/licenses

D’Oliveira, C. (2009). MIT opencourseware site improvements to meet the challenge ahead [Electronic mailing list message]. Retrieved from https://app.e2ma.net/app/view:CampaignPublic/id:12960.2373706887/rid:678c65eb285ead55b7a1ac7acb9 eaecf

Downes S. (2007). Models for sustainable open educational resources [Electronic version]. Interdisciplinary Journal of Knowledge and Learning Objects, 3, 29-34. Retrieved from http://ijklo.org/Volume3/IJKLOv3p029044Downes.pdf

Downes, S. (2001) Learning objects: Resources for distance education worldwide. The International Review of Research in Open and Distance Learning, 2(1). Retrieved from http://www.irrodl.org/index.php/irrodl/article/view/32/378

Doyle, H. J. (2005). Creating a public library of science [Powerpoint slides]. Utah: Open Education Conference. Retrieved from http://cosl.usu.edu/media/presentations/opened2005/OpenEd2005-Doyle.ppt

Eshuis, J. (2009). OER in practice: approach and experiences [Powerpoint slides]. Retrieved from http://labspace.open.ac.uk/course/view.php?id=4

Foote, T. (2005) Wikipedia [Powerpoint slides] Utah: Open Education Conference. Retrieved from http://cosl.usu.edu/media/presentations/opened2005/OpenEd2005-Foote.ppt

Fierce, D. (2009, January 4). Wikipedia raised \$6.2 million from donations. eFluxMedia Technology News. 
Retrieved from

http://www.efluxmedia.com/news_Wikipedia_Raised_62_Million_from_Donations_32526.html.

Metz, R. (2008). Wikipedia seeks $\$ 6$ million from donors. MSNBC. Retrieved from http://www.msnbc.msn.com/id/27560060/

MIT OpenCourseWare (2006). 2005 Program evaluations finding report. Retrieved from http://ocw.mit.edu/ans7870/global/05_Prog_Eval_Report_Final.pdf.

OpenCourseWare Consortium. (n.d.). About us. Retrieved from http://www.ocwconsortium.org/about-us/aboutus.html

Open University. (n.d.). International fellowships at the OU. Retrieved from http://www.open.ac.uk/international-fellowships/

Parry, M. (2009, September 3). Utah State U.'s OpenCourseWare closes because of budget woes. The Chronicle of Higher Education. Retrieved from http://chronicle.com/blogPost/Utah-State-Us-OpenCourseWare/7913

Sakai Project. (2005). Sakai Partners Program. Retrieved from http://www.sakaiproject.org/

Shadish, W., Cook, T., and Campbell, D. (2002). Experimental and quasi-experimental designs for generalized causal inference. Boston, MA: Houghton Mifflin.

Wiley, D. (2007). On the sustainability of open educational resource initiatives in higher education. OECD. Retrieved from http://www.oecd.org/dataoecd/33/9/38645447.pdf 